\title{
A FRAMEWORK FOR B2B CUSTOMER REACQUISITION: EVALUATING KEY DETERMINANTS TO WIN BACK LOST CUSTOMERS
}

\author{
Annie H. Liu, Victoria University of Wellington, New Zealand \\ Mark P. Leach, Loyola Marymount University, USA \\ Lou E. Pelton, University of North Texas, USA
}

\begin{abstract}
B2B sales organizations constantly search for opportunities to gain, retain, and grow business opportunities for their firms. Yet no matter how effective a company's CRM program or sales process is, inevitably, some customers will defect and switch to other suppliers. Although there are well-established sales processes to guide B2B salespeople in how to acquire new accounts and maintain customer relationships, few firms have formal win back strategy with procedures to diagnose loses and identify determinants in order to guide and train salespersons for regaining valuable lost customers. Left untrained, salespeople often deal with the problem of lost customers by re-approaching the lost customer without any advice, seeking ad hoc advice from peers or managers, or simply ignoring the lost account. The economic importance of reacquiring valuable lost customers in the B2B sector, along with the need to integrate reacquisition as the strategic second half of CRM warrants a systematic research to build a conceptual framework for B2B customer reacquisition. The current research integrates prior literature in relationship marketing, B2B sales, and service recovery to develop a conceptual framework for B2B customer reacquisition. Using critical incident techniques (CIT), our pretest study with eighteen B2B sales executives provides anecdotal evidence, and helps develop hypotheses and refine the proposed framework for future research.

Contributing to the B2B marketing and sales literature, this study is among the first to empirically investigate the processes for reacquisition efforts in $\mathrm{B} 2 \mathrm{~B}$ organizations and to propose a framework for identifying key determinants to win back valuable lost customers. The final results of this paper will provide new information to aid sales executives to: (1) identify critical salespersons' qualities and sales skills for reacquisition efforts that can be integrated in training and selection programs; (2) develop effective organizational relationship and support strategies to regain profitable business; and (3) identify types of customer defections and apply appropriate strategies to win them back. Adding to a more complete strategic understanding of CRM, the proposed conceptual framework can enable sales organizations to actively manage customers' experiences and firms' reputations based on the added knowledge of the determinants for customer defection and reacquisition.
\end{abstract}

References available upon request 